\title{
"Coordenador pedagógico: eu sou gay, e daí"? Inclusão excludente da juventude escolar
}

Tiago Dionisio da Silva ${ }^{1}$ Rafael Chaves Vasconcelos Barreto ${ }^{2}$ Guilherme Pereira Stribe ${ }^{3}$

\begin{abstract}
Resumo:
A partir do exercício da função de coordenador pedagógico (CP) em uma unidade escolar da Rede Pública Estadual do Rio de Janeiro este artigo traz reflexões a partir da tentativa de compreender as normas regulatórias de gênero presentes nos cotidianos escolares de jovens que se autodenominam homossexuais. A interação com os sujeitos ocorreu através do estabelecimento de conversa, realizadas mediante uma relação dialógica, propiciando a criação de um sentimento de cumplicidade e disponibilidade que tornou possivel uma ampla discussão em torno de questões relativas à heteronormatividade e às experiências que elas provocam no espaço escolar. Foram realizadas entrevistas com os oito jovens que se dispuseram a dialogar, contribuindo assim, com a tessitura de reflexões sobre a (re)produção dos estigmas sociais no espaço escolar e sobre a urgência de se (re)pensar o planejamento de estratégias de resistência nos cotidianos escolares, na tentativa de desmistificar a naturalização e normatização da suposta superioridade e supremacia das heteronormas e a fragilidade do direito a educação. Os avanços sociais relacionados a sujeitos LGBTQIA+ emergem no espaço escolar, contribuindo para o avanço dessas questões na sociedade.
\end{abstract}

\section{Palavras-chave:}

Espaço escolar. Direitos Humanos. Juventude. Dissidências sexuais.

\section{"Pedagogical coordinator: I'm gay, so what"? Exclusionary inclusion of school youth}

Abstract: From the exercise of pedagogical coordinator's function (CP) in the Rio de Janeiro's State Public unit school this article brings reflections from the attempt to understand the regulatory norms of gender present in the young people's school daily lives who call themselves homosexuals. The interaction with the subjects occurred through the establishment of conversation, carried out through a

\footnotetext{
1 Mestre em Educação, Professor da Secretaria de Estado de Educação do Rio de Janeiro (SEEDUC/RJ). E-mail: tiago_dionisio@hotmail.com.br. ORCID iD: https://orcid.org/0000-0002-6556-9025.

2 Doutor em Memória Social, Professor da Secretaria de Estado de Educação do Rio de Janeiro (SEEDUC/RJ). E-mail: rcvbarreto84@gmail.com. ORCID iD: https://orcid.org/0000-0002-3570-6084.

3 Doutor em Educação. E-mail: guilhermenpereira@gmail.com. ORCID iD: https://orcid.org/0000-0002-5633-4670.
} 
dialogical relationship, allowing the creation of a feeling of complicity and availability that made possible a wide discussion around issues related to heteronormativity and the experiences they induce in the school space. Interviews were conducted with the eight young people who were willing to talk, thus contributing to the fabric of reflections on the (re) production of social stigmas in the school space and on the urgency of (re) thinking about the planning of resistance strategies in everyday school daily, in an attempt to demystify the naturalization and standardization of the supposed superiority and supremacy of heteronorms and the fragility of the right to education. Social advances related to LGBTQIA+ subjects emerge in the school space, contributing to the advancement of these issues in society.

Keywords: School space. Human rights. Youth. Sexual dissent.

\section{"Coordinador pedagógico: ¿soy gay y entonces"? Exclusión de jóvenes escolares}

Resumen: A partir del ejercicio de la función de coordinadora pedagógica (PC) en una unidad escolar de la Red Pública Estatal de Río de Janeiro, este artículo trae reflexiones desde el intento de comprender las normas reguladoras de género presentes en la rutina escolar de los jóvenes que se autodenominan homosexuales. La interacción con los sujetos se dio a través del establecimiento de una conversación, realizada a través de una relación dialógica, permitiendo la creación de un sentimiento de complicidad y disponibilidad que posibilitó una amplia discusión en torno a temas relacionados con la heteronormatividad y las vivencias que provocan en el espacio escolar. Se realizaron entrevistas con ocho jóvenes que se mostraron dispuestos a dialogar, contribuyendo así al tejido de reflexiones sobre la (re) producción de estigmas sociales en el espacio escolar y sobre la urgencia de (re) pensar la planificación de estrategias de resistencia en la vida escolar cotidiana, en un intento de desmitificar la naturalización de la supuesta superioridad y supremacía de las heteronormas y la fragilidad del derecho a la educación. Los avances sociales relacionados con las materias LGBTQIA+ emergen en el espacio escolar, contribuyendo al avance de estos temas en la sociedad.

Palabras claves: Espacio escolar. Derechos humanos. Juventud. Disidencia sexual.

O que você pensa sobre o dia do orgulho gay? Eu me sinto feliz!

(Diadorim, estudante do 1 ano do EM, de 16 anos)

\section{Introdução}

A problematização sobre o funcionamento das normas de gênero e da sexualidade ainda são pouco estudadas no contexto da pesquisa brasileira (POCAHY, 2006). Do ponto de vista dessa preocupação, os trabalhos de Pocahy (2006), Rios (2004), Amaral (2012) e Duque (2009) expõem a complexa trama pela qual se busca compreender as sexualidades, em especial o estudo das dissidências sexuais, tendo como cenário o espaço escolar. Esses trabalhos informam o modo como jovens, que reivindicam a identidade homossexual - como no caso do público alvo do presente artigo - negociam e reinventam suas vidas a partir das redes de subjetividade e de significação que se constituem à margem das instituições que, supostamente, deveriam proteger esses sujeitos, tencionando o currículo, gerando demandas à equipe-técnico pedagógica, se apropriando do espaço-tempo escolar e, consequentemente, nos provocando a refletir sobre o fato deles estarem presentes na escola. Porém isso, por si só, não garante a inclusão desses(as) estudantes, nos levando para a seguinte questão: até que ponto o direito à educação é garantido? 
As experiências dissidentes juvenis de gênero e sexualidades no espaço escolar constituem-se o foco deste trabalho, fruto de experiência in loco, a partir da realização de oficinas pedagógicas e do exercício da função de coordenador pedagógico de um dos autores. Nosso intuito era investigar as marcas das normas regulatórias de gênero presentes nos contextos familiares, de convivência social e nos cotidianos escolares de jovens que não se identificam com a heterossexualidade.

Por considerarmos a escola um espaço-tempo político e ético de (re)construção e sistematização do conhecimento científico, além de ser também um lugar de socialização da juventude, tomamos as diretrizes (CONSED, 2019) indicadas pela Secretaria de Estado de Educação do Rio de Janeiro (SEEDUC/RJ) sobre as discussões dos Direitos Humanos e optamos por elaborar oficinas pedagógicas. $\mathrm{Na}$ tensão entre uma sugestão que soou como uma imposição do órgão central e as possibilidades existentes no ambiente escolar, a decisão tomada foi discutir a importância em se tratar os temas da violação e da garantia dos Direitos Humanos a partir do contexto social, econômico, cultural, sexual e racial da juventude inserida no ambiente escolar. Dessa forma, percebemos nesse espaço-tempo da escola um lócus propício e fecundo para o trabalho de temáticas historicamente invisibilizadas pelas políticas curriculares oficiais. Esse espaço-tempo é dotado de multiplicidades de culturas, sentidos, experiências, hibridismos e negociações que contribuem para a (re)construção da cultura da paz, do respeito aos Direitos Humanos e à cidadania, e ainda propicia o fortalecimento da democracia.

Assim, as oficinas pedagógicas foram construídas com o objetivo de discutir os Direitos Humanos e suas relações diretas e indiretas com a vida dos(as) estudantes. Tiveram como característica central a abertura de espaços de diálogos e aprendizados que buscaram colocar os(as) discentes no centro do processo. Nesse sentido, buscando potencializar a autonomia dos(as) estudantes através da escolha das temáticas que lhes interessaram mais, os(as) discentes puderam escolher entre os seguintes temas: 1) genocídio da juventude negra; 2) população LGBTQIA+; 3) feminicídio; 4) gênero, classe e raça; e 5) direito à cidade. Como é possível perceber pelas temáticas eleitas pelos/pelas estudantes, todas as oficinas ministradas versavam sobre temas relacionados à igualdade/equidade entre os sujeitos e direitos. Nessa direção, concordamos com Mary Rangel (2017, p. 24) ao afirmar que, para a construção de um mundo baseado na igualdade de direitos e para "um mundo plural e, ao mesmo tempo, mais humano", é necessária a construção de relações baseadas na valorização da diversidade epistemológica do mundo, no respeito e na superação dos processos de exclusões sociais.

As oficinas foram ofertadas aos estudantes do Ensino Médio Regular e Curso Normal (Formação de professores(as) em nível de Ensino Médio) e cada oficina contou com 40 vagas. Os(as) estudantes tiveram a liberdade de eleger o horário e a temática que mais lhes interessassem, levando em conta o período das aulas, bem como a agenda das avaliações. As inscrições ficaram a cargo do Grêmio Estudantil. Nosso intuito foi construir táticas para construção da autonomia discente sem a tutela dos(as) professores(as) e da equipe diretiva na condução obrigatória de participação nas atividades.

Durante e após as oficinas, continuamos percebendo que as tensões no espaço escolar continuaram e nossas inquietações persistiram, pois observamos uma presença numerosa de estudantes que se declararam homossexuais na unidade escolar. Ao mesmo tempo, parte desses discentes chamavam atenção do corpo docente por serem apáticos, introvertidos, acumularem notas abaixo da média, enquanto outro grupo se destacava pela indisciplina. Entretanto, defendemos que esses comportamentos são ações que tensionam o espaço escolar, o currículo, a falta de representatividade e o acolhimento. Dessa forma, nós percebemos que apesar dos(as) estudantes homossexuais estarem presentes no espaço-tempo escolar, eles(as) permanecem em uma espécie de inclusão excludente.

Tais reflexões surgiram a partir de observações feitas durante as oficinas, quando inúmeros estudantes, que eram extremamente tímidos, nos procuraram individualmente para se inscreverem nas oficinas cujo tema versava sobre gênero e sexualidades. Cabe ressaltar que esse assunto não vem sendo discutido nos currículos escolares, muitas vezes silenciado no espaço escolar, não incorporado 
ao cotidiano dos discentes quando estão na escola. Então, para tentarmos compreender essa situação, entrevistamos os(as) estudantes que se dispuseram dialogar conosco sobre tais questões.

Realizamos entrevistas com oito alunos(as) que aqui serão nomeados ficticiamente ${ }^{1}$ a fim de que respeitemos a ética da pesquisa, preservando assim a identidade dos(as) entrevistados(as). Nossas conversas com os(as) adolescentes se deram de maneira pré-organizada por nós. Queremos dizer que fomos a campo com um roteiro de perguntas abertas, o que nos permitiu entrevistar sem circunscrever a resposta dos(as) participantes a uma ou duas possibilidades. Nosso roteiro era apenas uma forma de não nos perdermos na conversa, mas não quer dizer que o aplicamos dogmaticamente. Assim, seguirão ao longo desse artigo algumas reflexões e análises das falas no que tange a escola, educação, homofobia e sexualidades.

As análises dessas entrevistas deram origem a este artigo, dividido em três seções: a primeira discute sobre dissidências sexuais e espaço escolar, na segunda abordamos a educação sobre Direitos Humanos e na terceira analisamos as entrevistas sobre a perspectiva dos Direitos Humanos e como as dissidências sexuais atravessam o cotidiano escolar.

Os relatos produzidos pelos jovens da pesquisa sobre suas experiências escolares evidenciaram a pluralidade de concepções sobre o espaço escolar e como sua sexualidade interfere em suas vidas. Portanto, compreender a relação dos estudantes homossexuais com esse espaço se faz necessário, uma vez que eles passam uma boa parte da infância e juventude em experiências socioeducativas na escola, de modo que não há como negar a importância em conhecer a relação dos jovens com a escola. Isso nos permitiu construir reflexões sobre as relações de poder que (re)produzem e legitimam discursos que colocam em funcionamento e manutenção das heteronormas no espaço escolar.

Esta pesquisa caracterizou-se como qualitativa, uma vez que foram realizadas observações diretas e indiretas, procurando interpretar os significados que os indivíduos dão às suas ações, no meio em que constroem suas vidas e suas relações. Segundo Lüdke e André (1986, p. 26) tanto a entrevista, quanto a observação ocupam um lugar privilegiado nas novas abordagens de pesquisa educacional. Usada como o principal método de investigação ou associada a outras técnicas de coleta, a observação possibilita um contato pessoal e estreito do pesquisador com o fenômeno pesquisado, o que apresenta uma série de vantagens. Essa experiência direta é, sem dúvida, o melhor teste de verificação da ocorrência de um determinado fenômeno.

Dentre as várias formas em que uma pesquisa qualitativa pode ser desenvolvida, a etnografia se apresenta como a possibilidade para a investigação da realidade cotidiana da escola que melhor atende aos anseios deste estudo. Essa abordagem antropológica na educação convida ao exercício da crítica cultural, trazendo à nossa visão os significados sociais que grupos diversos manifestam em situações semelhantes e, sobretudo, complexifica a visão do próprio ato educativo (DAUSTER, 2001).

Os dados que subsidiaram essa análise foram produzidos por meio da aplicação dos questionários e observação participante (ocorrendo ao longo das oficinas). Tal abordagem metodológica reconhece a pessoa pesquisadora enquanto um instrumento de investigação e requer um contato direto e prolongado com o contexto analisado. Com Correia (2009), entendemos como Observação Participante a totalidade do trabalho de campo, desde a chegada das pessoas investigadoras ao contexto de pesquisa, compreendendo as negociações necessárias para conseguir acesso a este, às visitas prévias e à observação/interação com os indivíduos envolvidos.

Os entrevistados apresentaram, em suas narrativas, diferentes formas de lidar com as suas sexualidades em uma sociedade cisheteronormativa. Todavia, também se pode observar nos relatos que informações e discussões sobre as questões LGBTQIA $+^{2}$ nos diferentes espaços contribuem para diminuir a discriminação e o preconceito.

1 Os nomes fictícios eleitos para representar os(as) alunos(as) são todos personagens da Literatura Brasileira com vivências tratadas como homoeróticas, a fim de homenagear obras e escritores(as) que ousaram trazer para o cenário literário nacional a abordagem desse tema.

2 Lésbicas, Gays, Bissexuais, Transexuais, Queers, Intersexuais, Assexuais e demais sexualidades consideradas dissidentes. 


\section{Educação em Direito Humanos: um diálogo necessário}

Em 1948, a Declaração Universal dos Direitos Humanos aprovada pela Organização das Nações Unidas (ONU, 1948) proclama que os direitos humanos são um ideal comum que, pela educação e o ensino, deve ser atingido por todos os povos e nações, desde o âmbito pessoal e individual até as mais altas esferas governamentais, local e globalmente. A própria ONU tem como um de seus objetivos "gerar uma atmosfera mundial de respeito pela pessoa e por sua dignidade" (SACAVINO, 2008, p. 26). Desse modo, tem sido construída uma série de instrumentos que balizam esse ideal comum dos direitos humanos. Um dos mais importantes é a Carta Internacional de Direitos Humanos das Nações Unidas (ONU, 1948), composta pela Declaração Universal dos Direitos Humanos (1948), pelo Pacto Internacional de Direitos Civis e Políticos (1966), pelo Pacto Internacional de Direitos Econômicos, Sociais e Culturais (1966), pelo Protocolo Facultativo ao Pacto Internacional de Direitos Civis e Políticos (1966) e pelo Segundo Protocolo Facultativo ao Pacto Internacional de Direitos Civis e Políticos (1989).

A Declaração Universal dos Direitos Humanos (ONU, 1948) proclama que a educação e o ensino são meios pelos quais os conteúdos da própria Declaração compreendem um horizonte comum, um objetivo a ser alcançado por cada indivíduo e por cada órgão da sociedade. Apesar de estes não serem essencialmente documentos curriculares, ou seja, não terem sido construídos com o objetivo de orientar as atividades educacionais, a Declaração Universal dos Direitos Humanos indica que é pela educação e pelo ensino que seu conteúdo será disseminado.

Ramos (2010) pontua que, apesar da importância política histórica da Declaração Universal dos Direitos Humanos, esta representa uma articulação discursiva marcada pelo cenário trágico que urgia por uma condenação aos horrores perpetrados na guerra e pela necessidade de se estabelecer a paz, considerando-a viável a partir de compromissos que se desdobrem em implementação de ações práticas. Logo, representa, segundo a própria autora, inspirada em Boaventura Souza Santos (1997), um localismo globalizado, ou seja, uma produção cultural específica que é enunciada como universal, ou como válida para todos. Sob a ótica da teoria do discurso, compreende-se que a produção de sentidos não é possível nesta lógica; as demandas sociais vão funcionando como exterior constitutivo através do qual os sentidos serão produzidos. Tendo em vista que essas demandas são provisórias, os sentidos constituídos em cadeias de equivalência formadas a partir de tais exteriores constitutivos também o serão. Assim, os sentidos são sempre precários e contingenciais, na medida em que surgem para dar conta de demandas.

E pensando nesse caminhar, temos na Educação um ambiente fértil para trabalhar esses temas e pensar numa sociedade futura onde esses ideais estejam presentes. Desse modo, a próxima parte desse trabalho avançará na articulação dessas temáticas.

Apesar da relação próxima entre direitos humanos e educação desde os anos 2000, essa articulação ficou mais evidente no cenário brasileiro, ganhando políticas específicas (FRANGELLA; RAMOS, 2013). Segundo texto da terceira versão do Programa Nacional de Direitos Humanos (PNDH-III), o Ministério da Educação (MEC) e a Secretaria de Direitos Humanos ${ }^{3}$ (SDH) tem se esforçado em promover o eixo de educação em direitos humanos, por considerarem-no o mais estratégico (SDH/PR, 2010).

O desejo pela articulação dos direitos humanos com a educação, bem como de outras pautas, está relacionado ao sentido que a educação assume socialmente. Educar é um movimento de aproximação semântica, é um movimento de aculturação. Diferentes tipos de modelos educacionais priorizam aquilo que consideram mais adequado para o sujeito que pretendem formar. Toda educação é adjetivada, mesmo que não explicitamente.

3 Órgão do Governo Federal brasileiro que, sendo criado em 1997, tem status de ministério, apesar da nomenclatura de secretaria. 
Educação em direitos humanos supõe uma proposta educativa que tome os princípios dos direitos humanos como eixo; emerge como resposta a processos educativos, de diferentes naturezas, que produzem formas de ver o mundo que violam a dignidade humana. Essa é uma preocupação que inquieta pesquisadores e ativistas há muito tempo. Aida Maria Monteiro Silva, em sua tese de doutoramento defendida em 2000, apresenta que, à época, 35\% dos jovens eram indiferentes à democracia ou à ditadura (SILVA, A., 2000). Atualmente, com a crise política e o golpe que culminou no impeachment da então presidente Dilma Rousseff, um movimento com caráter apartidário (ou de descrença nas representações partidárias) tem se intensificado. Para a autora, concordando com diversos outros pesquisadores (BOBBIO, 2004; CHAUI; SANTOS, 2013; RAMOS, 2010, 2011; SANTOS, 1997, 2014), a democracia é um princípio básico na defesa dos direitos humanos; e a cidadania se dá por meio da participação efetiva dos sujeitos, manifestando a soberania popular.

É preciso perceber que, muitas vezes, o discurso sobre direitos humanos assume um tom monofônico de pertencimento a determinado modelo baseado em adequação e conformidade. Talvez isso tenha relação com o fato de a maior parte da população mundial ser objeto de discussão sobre direitos humanos, e não sujeitos de tais direitos (SANTOS, 2013). Ou seja, há pessoas que, não se adequando ao que seria reconhecido como cidadão, ou sujeito de direitos, não tem seus direitos garantidos, tampouco como reivindicá-los.

A educação em direitos humanos assume, portanto, uma posição estratégica uma vez que tem por objetivo produzir sentidos que diluam as hierarquias sociais e possibilitem que as pessoas se reconheçam como sujeitos de direitos; que empoderem os sujeitos; e que ensinem sobre as atrocidades cometidas ao longo da história para que não se repitam. Segundo Candau (2006, p. 231), educar em direitos humanos é

Um processo sistemático e multidimensional orientado à formação de sujeitos de direito e à promoção de uma cidadania ativa e participativa; a articulação de diferentes atividades que desenvolvam conhecimentos, atitudes, sentimentos e práticas sociais que afirmem uma cultura de direitos humanos na escola e na sociedade; processos em que se trabalhe, no nível pessoal e social, ético e político, cognitivo e celebrativo, o desenvolvimento da consciência da dignidade humana de cada um; processos em que [...] estejam presentes uma: ${ }^{\star}$ pedagogia da indignação, ${ }^{*}$ pedagogia da admiração, ${ }^{*}$ pedagogia de convicções firmes; uma dinâmica educativa ativa e participativa que promova o trabalho coletivo, a autoestima e o autoconceito positivos, o 'empoderamento' de todas as pessoas, particularmente das oriundas de grupos excluídos, e a valorização das diferentes culturas brasileiras.

Quando se discute a incorporação da temática dos direitos humanos aos processos educativos de forma sistemática e explícita, há uma variedade de possibilidades que emergem, como, por exemplo, incluir enquanto disciplina ou como temática transversal. Klainer e Fernandéz (2014) indicam que, atrelado a este movimento de consolidação da educação formal por uma via curricular, é fundamental fomentar a sensibilização docente para as questões que perpassam a educação em direitos humanos. Sensibilizar-se para os direitos humanos passa por desenvolver empatia para com o outro, extrapolando a ideia de que os próprios direitos, em nível individual, podem ser violados, compreendendo que a dignidade humana é condição básica a ser assegurada a todos os seres humanos. Esta sensibilização não ocorre de forma homogênea, podendo, desdobrar-se em posicionamentos contraditórios, uma vez que a teia discursiva construída socialmente é complexa. Um exemplo muito explícito são discursos de valorização da vida, quando se trata da temática do aborto por alguns grupos, mas sem o mesmo engajamento pró-vida por pessoas que passam fome.

A educação em direitos humanos, portanto, pauta-se em experiências dialógicas, que busquem enfrentar outras pedagogias, explícitas ou não, que produzam discursos perversos, excludentes e que promovam as desigualdades sociais. Educar em direitos humanos é assumir a inclusão e a dignidade humana como horizonte de sentido, tendo como pano de fundo as juventudes, tema que discutiremos a seguir. 


\section{Juventudes escolares e dissidências sexuais: tensões, desafios e perspectivas}

Inicialmente, é necessário considerar que a juventude é uma construção social, histórica e cultural. Isso significa dizer que existe "[...] uma juventude pobre, rica, indígena, negra, popular, nordestina [...], que ultrapassa os limites etários e celebra diferentes modos de sentir, pensar, dançar e de atuar no mundo" (COSTA, 2005, p. 49). Nesse sentido, a ideia de jovem é construída social e culturalmente e, portanto, a cada contexto histórico, econômico, cultural e social são construídas novas concepções de jovem ou de uma juventude. Como afirma Levi e Schmitt (1996, p. 14),

A juventude como construção social: em nenhum lugar, em nenhum momento da história, a juventude poderia ser exclusivamente biológica ou jurídica. Sempre e em todos os lugares, ela é investida também de outros símbolos e de outros valores. De um contexto a outro, de uma época a outra, os jovens desenvolvem outras funções e logram seu estatuto definidor de fontes diferentes: da cidade ou do campo, do castelo feudal ou da fábrica do século XIX, da organização do campagnonnage no ancién régime ou na cidade antiga.

Então, partindo dessa perspectiva sociocultural, nosso foco de análise não é discutir a sociabilidade ou a cultura juvenil, mas sim como uma juventude que está no espaço escolar, a partir das suas experiências reconfiguram e de sua autoidentificação como gay/lésbica, se relacionam e reconstroem o espaço escolar. Assim, por juventudes escolares, entendemos os jovens que estão regularmente matriculados em uma instituição de ensino, e é para esses jovens inseridos nesse referido espaço que seguem nossos olhares.

Considerando que boa parte de nossas infâncias e juventudes se constroem com experiências socioeducativas na escola, não há como negar a importância de conhecer a relação dos jovens pesquisados, principalmente levando em consideração suas sexualidades, já que suas subjetividades desorganizam o espaço escolar e coloca em cheque o discurso de que todos os cidadãos têm garantia à educação, tendo em vista que estes, apesar de estudarem, muitas vezes não estão (ou se sentem) incluídos nessa instituição. Essa questão nos permitiu indagar sobre as relações de poder que (re)produzem e legitimam discursos que funcionam como manutenção às heteronormas e se tornam obstáculos a um direito social (educação).

Compreendemos a escola como a instituição de socialização e difusão do conhecimento acumulado nos campos das ciências e das artes, mediada por meio dos conteúdos curriculares e relação pedagógica entre os sujeitos escolares, de princípios fundamentais, normas e valores gerais da sociedade, ou seja, uma instituição encarregada da conservação e da transmissão de uma cultura que se pressupõem legítima - para alguns, elitista e excludente; para outros, detentora de um potencial de libertação e emancipação. No entanto, o fato é que há um esvaziamento de suas funções sociais, pois acreditamos que a escola vem tentando se manter como organização tradicional mediante ao estabelecimento de regras, normas, procedimentos legais e burocráticos que visam regular o funcionamento do sistema educacional não inclusivo e reprodutor do status quo que defende a manutenção da desigualdade social e intelectual. Alheia à existência de qualquer projeto educativo democrático, objetivos ou conteúdos, a regulação da organização parece ser o último recurso na tentativa de mantê-la em pé.

Entretanto, as falas trazidas pelos estudantes mostram que esse recurso não está funcionando, colocando a escola como um mero espaço receptor. Desse modo, pensando a necessidade de se repensar esse lugar da escola e o modo como ela se configura como meio de reprodução de um sistema, é imprescindível que se repense o currículo, uma das ferramentas utilizadas como forma de manter uma determinada norma. A fim de refletir sobre essa questão, vejamos a seguinte citação: 
Os currículos escolares constituem os conflitos e os jogos de interesses de múltiplos grupos. Essa dinâmica cotidiana, sob vários aspectos naturalizada, nos leva a pensar que não se trata apenas de criticar os conteúdos e a forma como os saberes estão presentes nos materiais didáticos, nas orientações governamentais e nas avaliações escolares. Segundo Caetano (2016), um coletivo de sujeitos pode, no mesmo tempo e espaço, mesmo que de forma provisória, subalternizar e ser subalternizado. Isso porque essas dinâmicas não acontecem em um vazio cultural, político, ideológico, econômico, religioso e se inter-relacionam diretamente com as dinâmicas de gênero, raça, classe e identidade sexual. Daí a necessidade de problematizar cotidianamente os conhecimentos universalizados pelos currículos que, mesmo quando coletivamente construídos, refletem os jogos de poder das/nas escolas. (CAETANO; GOULART; SILVA JUNIOR, 2016).

Tudo isso mantém o status quo de uma educação ainda carregada de preconceito e discriminação, que incide diretamente no espaço escolar. Para Arroyo (2011), a escola e os conhecimentos curriculares estão no meio das disputas políticas que ocorrem em torno das identidades. Nesse sentido, a ideia de conhecimento nos currículos como um artefato relativamente neutro, tornando-o apenas um processo psicológico que se estabelece através da cognição, tem permitido uma falaciosa e letal despolitização quase integral da cultura eurocentrada, branca, judaico-cristã, colonizada, burguesa e heterossexual que as escolas universalizam através de suas práticas pedagógicas cotidianas. Podemos observar isso através da fala do aluno abaixo transcrita:

A escola deveria abraçar mais os alunos(as) LGBT e tirar um dia pra colocar símbolos LGBT e etc pra fazer a gente se sentir bem e amado, já que não somos aceitos pela nossa própria família. Sim, porque na escola aonde estudo a maioria são LGBT então a gente meio que acaba se tornando uma mini família. (Riobaldo, 17 anos, 3o ano do EM).

Em se tratando especificamente do tema deste artigo, Abramovay, Castro e Silva (2004, p. 278) mostram que muitas vezes os professores não somente silenciam as diversas situações de violência direcionadas a determinados estudantes que manifestam sexualidade distinta do padrão heterossexual, "mas colaboram ativamente na reprodução de tal violência". Essa colaboração com a perpetuação do olhar de correção, tem como pretensão reproduzir, direta ou indiretamente, a norma heterossexual. Essa atribuição de um gênero defeituoso (BUTLER, 1993) é comumente utilizada nas práticas homofóbicas ao inferir que um homem gay é "feminizado" e uma mulher lésbica é "masculinizada". A fala abaixo retrata essa questão:

Sim várias vezes fui zoado! Os meus colegas da escola me zoam muito, mas não ligo. Só acho que a escola tinha que fazer alguma coisa. (Diadorim, 16 anos, 1o ano do EM).

Sim, desde olhares de censura até humilhações e agressões. (Saul, 18 anos, 3o ano do EM).

Um pouco, tem muitos alunos tóxicos que fazem brincadeiras de mau gosto. Sim, muitas pessoas já ficaram falando muitas coisas sobre minha sexualidade. (Lucas, 15 anos, 1o ano do EM).

Diante dessa fala, fica claro como o espaço escolar pode não ser acolhedor, gerando insegurança, impactos físicos e emocionais na vida dos jovens, em especial, os da classe popular, uma vez que os recursos financeiros dificultam as soluções. Isso porque, ao não questionarmos o regime heterocentrado, a visão de que a heterossexualidade é natural e superior, as inúmeras práticas homofóbicas continuarão emergindo como estratégias para não expor os limites e as fragilidades das heteronormas.

As identidades (sexuais) dos jovens estudantes, em sua relação com o espaço escolar, estão a todo tempo tensionando e sofrendo a interpelação dos currículos. Considerando esse cenário, foi possível constatarmos que os(as) estudantes entrevistados estão todos com idade/série defasada, com exceção das duas meninas. Será que isso não é resultado de um espaço escolar agressivo e 
não contemplativo das múltiplas sexualidades inerentes aos seres humanos? Nesse sentido, como uma instituição escolar ideal deveria lidar com essa questão? Como tornar o ambiente mais seguro, acolhedor e que garanta aos(as) estudantes uma trajetória escolar mais tranquila?

Tabela 1 - Idade x Escolarização

NOME IDADE ANO ESCOLAR

\begin{tabular}{cll}
\hline Naim & 17 anos & 10 ano do EM \\
\hline Amaro & 19 anos & 20 ano do EM \\
\hline Raul & 19 anos & 3o ano do EM \\
\hline Riobaldo & 17 anos & 3o ano do EM \\
\hline Lucius & 19 anos & 10 ano do EM \\
\hline Lucas & 15 anos & 10 ano do EM \\
\hline Saul & 18 anos & 3o ano do EM \\
\hline Diadorim & 16 anos & 10 ano do EM
\end{tabular}

Fonte: Elaborado pelos autores.

Observa-se na tabela acima que entre 8 (oito) entrevistados, apenas 3 (três): Naim, Lucas e Diadorim estão com a idade adequada ao ano escolar cursado, portanto a defasagem-série aparece como um complicador e pode ser compreendida como uma marca da trajetória escolar desses jovens. Inúmeros fatores podem estar por trás dessa situação: o espaço escolar é desinteressante; a sexualidade; e o trabalho para contribuir coma renda familiar, portanto são questões inerentes ao universo escolar, logo podem ser refletidas tendo a escola como protagonista nessas discussões a partir dos seus sujeitos principais: por serem da classe popular, determinadas questões, como a do trabalho, interferem no processo ensino/aprendizagem desses estudantes.

Reprovei duas vezes por falta. (Naim, 17 anos, 1o ano do EM).

Reprovei duas vezes, um ano foi por bobeira e outro ano eu estava passando por uma situação muito difícil na minha casa: estava me assumindo gay. (Amaro, 19 anos, 2o ano do EM).

Uma vez, pois a escola estava muito chata. (Raul, 19 anos, 3 ano do EM).

Reprovei várias vezes, pois não conseguia conciliar o trabalho com a escola. (Lucius, 19 anos, 1 a ano do EM).

A escola não pode desconsiderar que a adolescência se caracteriza como um período de desenvolvimento marcado por intensas transformações biopsicossociais, impulsionadas pelas experiências culturais e pelas mudanças hormonais da puberdade. Ainda que sobre o tema resida um complexo emaranhado discursivo, a adolescência constitui-se, no geral, como uma fase de transição entre os anos da vida infantil e a adulta. Nesse período, é observado um acentuado desenvolvimento corporal, de vivências emocionais, de construções de redes interpessoais de amizades etc., que interpelam a identidade, assumindo performances e mediando a construção de redes de sociabilidades (SCHOEN-FERREIRA, 2010). Dentre as inúmeras modificações vivenciadas na adolescência, sem dúvida, uma das mais significativas está relacionada à sexualidade. Ainda que seja indeterminado o período cronológico que dará conta das transformações do corpo na adolescência, no geral, observamos que elas ocorrem geralmente entre os 10 e 16 anos.

Entretanto, os limites cronológicos da adolescência são definidos pela Organização Mundial da Saúde entre 10 e 19 anos (WHO, 1986). No Brasil, o Estatuto da Criança e do Adolescente (ECA), instituído pela lei federal no 8.069 de 1990 (BRASIL, 1990), considera criança a pessoa de até 12 anos de idade incompletos e define a adolescência entre a faixa etária de 12 a 18 anos (Art. 2) - em casos excepcionais, e quando disposto em lei, o Estatuto é aplicável até os 21 anos de idade (Art. 121 e 142). 
Portanto, independentemente da perspectiva, o período da adolescência e toda a profusão sexual que ele acarreta é vivido, quando respeitada a legislação brasileira, na escola.

Nesse sentido, vale destacar que o período do Ensino Médio se torna determinante na construção da personalidade dos jovens uma vez que:

[...] representa uma fase de formação não apenas intelectual-cognitiva, mas também de preparação para a vida adulta, um momento de construção de identidades e de pertencimentos a coletivos distintos. É uma fase de ruptura, de re-construção. Os(as) jovens, nesse período, não estão apenas aprendendo matemática, geografia, física, entre outras disciplinas. Não é apenas um saber externo, objetivo, sistemático, que importa nesse momento. É também um período de constituição de um saber sobre si, de busca de significados do ser homem ou ser mulher, de construção da identidade sexual. Pesquisas sobre alunos(as) do ensino médio devem, portanto, abranger não somente aspectos relativos aos conteúdos considerados necessários para a formação geral ou para a preparação de suas futuras escolhas profissionais. É preciso desenvolver uma escuta atenta e observação cuidadosa de questões identitárias que refletem sobre a vida desses estudantes e que certamente terão impacto em suas decisões futuras, tanto na trajetória pessoal como profissional. (WELLER, SILVA, CARVALHO, 2011 p. 275-276).

Sob a lógica racional de organização dos conteúdos e das práticas intencionais da escola, o currículo busca precisamente modificar ou formar os sujeitos para a vida ocupacional e em sociedade na fase adulta. De forma mais ampla, o conjunto de teorias do currículo deduzem um modelo de conhecimento importante, a partir de descrições sobre o tipo de indivíduo que elas consideram ideal, para constituir a sociedade e garantir o seu planejamento e os seus princípios de cidadania. Nesses jogos de poder originam-se os silêncios em torno das identidades sexuais dissidentes, a exemplo de homossexuais, travestis e transexuais, que se aprofundam, quando os cruzamos com as dimensões de gênero, raça/etnia e classe. As falas abaixo retratam um pouco das expectativas dos alunos da amostra com relação a abordagem desses temas na escola:

A escola poderia fazer mais palestras, sempre. Ir às turmas sempre e falar em respeito, porque respeito é a base de tudo. (Amaro, 19 anos, 20 ano do EM).

Mostrar mais conteúdos sobre o assunto, pois as pessoas precisam entender que temos as nossas diferenças, mas somos iguais, temos direitos. (Raul, 19 anos, 3o ano do EM).

Palestras ensinam muito, ajudaria muito. Ah! A educação que vem de casa... Mas a que vem de casa será uma educação homofóbica e a escola tem que combater isso. (Lucius, 19 anos, 1 1o ano do EM).

Proporcionar mais debate, palestras e campanhas sobre a conscientização e que falem sobre como o preconceito deve ser abandonado. (Saul, 18 anos, 3o ano do EM).

Essas considerações se inserem em um momento de alterações substanciais nos discursos científicos que, por sua vez, não estão ausentes dos debates políticos que envolvem o contexto de movimentos sociais emergentes. Ao ponderar o gênero, as identidades sexuais, a raça/etnia e a classe como questões a se debruçar, ao invés de tratar essas discussões como algo que não precisam de explicação dentro do ambiente escolar, percebemos que é necessário alocar esses debates em torno das diferenças na agenda das investigações acadêmicas, na elaboração de marcadores para as políticas públicas e para os currículos escolares.

Sendo assim, as perguntas sobre o tipo de indivíduo desejável para uma determinada sociedade são oportunas para pensar em que posições nos currículos estão os saberes e as narrativas daqueles e daquelas que subvertem as performances e/ou posições hegemônicas sexuais, étnico-raciais e de classe. Ainda que saibamos que cotidianamente se disputam saberes nas escolas, as tentativas de orientá-los por uma determinada perspectiva são refletidas em suas 
dinâmicas didático-curriculares. Dessa forma, podemos pensar que a escola é um espaço em que se disputam duas perspectivas: a monocultural e a que envolvem as narrativas e memórias dos coletivos que historicamente foram subalternizados e silenciados. Na escola tais questões se reproduzem, conforme verificamos nas falas a seguir:

Não, não me sinto acolhido na escola, porque muitos alunos me zoam e ninguém faz nada. (Diadorim, 16 anos, 1o ano do EM).

Sim, felizmente me sinto seguro na minha escola. A maioria dos colegas e amigos nos unimos e dizemos 'NÃO' ao preconceito. (Saul, 18 anos, 3o ano do EM).

Sim, porque na escola onde estudo a maioria são LGBT, então a gente meio que acaba se tornando uma mini família. (Riobaldo, 17 anos, 3o ano do EM).

Conforme Arroyo (2011), nessas relações de disputa, o silenciamento das vozes destoantes do discurso central tem como objetivo a (re)produção de indivíduos com características desejáveis, do ponto de vista de um funcionamento social normalizado e hegemônico. Ao questionar o tipo de indivíduo que deve comportar a sociedade, Tomaz Tadeu da Silva (1999) nos impõem os seguintes questionamentos e cada pergunta leva, em si, para uma determinada performance e corresponde a determinados tipos de saberes da organização didático-curricular.

Será a pessoa racional e ilustrada do ideal iluminista de educação? Será a pessoa otimizadora e competitiva dos atuais modelos neoliberais de educação? Será a pessoa ajustada aos ideais de cidadania do moderno estado-nação? Será a pessoa desconfiada e crítica dos arranjos sociais existentes, preconizada nas teorias educacionais críticas? (SILVA, T., 1999, p. 15).

Ao entrever a lógica que operou a elaboração das perguntas feitas por Silva (1999), outras perguntas emergem: quais as táticas criadas pelos indivíduos para subverter as lógicas normatizadoras nas escolas? Sobre quais modelos de mulheres e homens, presentes nas várias teorias pedagógicas, os indivíduos, na escola, criam suas subversões? Como os currículos se rearranjam frente às táticas criadas pelos indivíduos na escola? Como as dissidências interpelam os currículos?

\section{Dissidências sexuais e seus atravessamentos no espaço escolar}

Compreender como o jogo normativo de gênero e da sexualidade regula a vida dos estudantes homossexuais é importante, pois, assim como Meyer (2012) argumenta, há necessidade de colocarmos em evidência as relações sociais diversas intra e extramuros da vida escolar, atingindo e conformando os corpos/sujeitos escolares. Ao entrevistar o jovem Amaro, perguntamos se ele já havia sofrido homofobia na escola, e tivemos a seguinte resposta:

Sim, muito. Se você é gay e ficar dentro do armário a escola vai te cobrar, mas se você for gay declarado, assumido, se for popular, pois eu sou um gay popular, e impor respeito, você não sofre, eu nunca sofri. Nem no Dom Pedro nem em outras escolas. Só na E.M. Manoel Reais, pois não era assumido. (Amaro, 19 anos, 2 o ano do EM).

$\mathrm{Na}$ fala de Amaro é possível observar algo muito interessante, que é uma cobrança externa por parte da comunidade escolar pela "saída do armário". Parece ficar implícito na fala do jovem que o gay não assumido sofrerá mais preconceito caso não torne público a sua orientação sexual. Na prática cotidiana é o que exatamente acontece: gays não assumidos são o alvo preferido das 
brincadeiras homofóbicas. Parece existir um sentimento cisnormativo ${ }^{4}$ que deseja que todos confessem "o erro"; que torne público o que é privado para que seja julgado normal ou anormal. Por outro lado, parece também que o gay assumido não tem uma vida calma e tranquila na escola. Como Amaro mesmo diz e deixa entrever em sua resposta, se assumir e dizer que é gay figura um passo de coragem e de posse da própria história, o que faz com que as armas do opressor sejam enfraquecidas. Queremos dizer, como alguém com intenção de ofender, pode chamar alguém de "bicha", "viado", "gay" se o próprio já afirma ser?

Ainda na fala de Amaro, é possível refletir que quanto mais cedo se diz ao mundo o que se é, aparentemente há menor cobrança por uma autoafirmação. Nisto não deixa de existir uma prática violenta, aparentada com as práticas inquisitoriais dos séculos XVII, XVIII e XIX. Mesmo se assumindo gay, e assumindo para si todos os percalços gerados pelos condicionamentos a serem enfrentados por isso, Amaro não se viu livre de sofrer a homofobia na pele. Cabe ressaltar que não queremos desenvolver uma análise que busque dizer apenas o que pessoas da comunidade LGBTQIA+ sofrem e sentem, mas sim de exemplificar e corroborar nossas hipóteses, através dos relatos de alunos(as), que nenhuma pessoa gay, lésbica, travesti, trans, dentro todas as outras denominações, passam pela escola sem que ela deixe uma experiência de LGBTQIA+fobia. Queremos argumentar, como já dito, que antes de ser um ambiente plural, a escola ainda, infelizmente, permanece sendo um espaço opressor para essa comunidade - apesar dos esforços de profissionais comprometidos com uma ética universal e com a promoção integral da política dos Direitos Humanos.

Já sofri homofobia sim, mas não na rua. Em casa, porque meu pai é super homofóbico. Eu me assumi quando tinha 14 anos e a gente morava em um quintal de família. Eu falei com minha tia e me assumi, daí minha vida virou um inferno. Apanhei muito, fui parar no conselho tutelar e no psicólogo, aí foi quando todo mundo viu que eu não estava maluco, que eu estava com a cabeça boa, que isso não é uma doença. Hoje em dia minha mãe está aceitando, quer dizer, ninguém é obrigado a aceitar nada, ela tem que me respeitar. Então ela está me respeitando, mas meu pai é irredutível. Há poucos dias eu e meu pai saímos na porrada. Nós moramos na mesma casa, mas não nos falamos. (Amaro, 19 anos, 2o ano do EM).

Quando perguntado se já sofreu homofobia em outros contextos, como vimos acima, Amaro diz que nunca vivenciou esse tipo de preconceito na rua, mas sim no local em que deveria ser menos provável: dentro de sua própria casa. Voltando para a resposta anterior do entrevistado, ele afirma que se assumir diminui o sofrimento dentro da escola, porém, contraditoriamente, dentro de casa essa lógica muda. Expor essa identidade se torna algo tão grave que laços familiares são rompidos (tal rompimento se torna aceitável), situações de violência entre pai e filho se torna algo, aparentemente, normalizado, nessas situações. Desse modo, fica claro que a não aceitação da homossexualidade, em nome de uma moralidade, recai sobre um discurso falacioso, já que a violência, principalmente de um pai para filho, deveria ser se visto como uma ação não aceitável. Podemos afirmar que o que chamam de "luta" pela moralidade, na verdade, é uma luta pelo direito ao ódio a tudo que se coloca como diferente do que é tratado como norma.

Seguindo com outras respostas, vejamos o seguinte fragmento:

Acho que deveriam fazer palestras sobre LGBT, falar mais sobre o assunto para todos entender, que não há diferença entre ninguém que todos somos iguais. (Lucius, 19 anos, 1o ano do EM).

4 Cabe explicar que as categorias cisgênero e transgênero estão relacionadas à identidade de gênero da pessoa, como ela percebe seu corpo em relação ao sexo com o qual nasceu. Desse modo, dizemos que o indivíduo é cisgênero quando sua identidade de gênero coincide com o seu sexo biológico e transgênero quando o indivíduo percebe seu gênero em "desacordo" com seu sexo biológico, não se identificando assim com seu corpo. 
Essa fala de Lucius surgiu quando perguntamos sobre o que a escola poderia fazer para melhorar a convivência de pessoas LGBTQIA+ na sociedade. A resposta desse estudante nos faz retornar para a questão da formação continuada para os professores, para a interação entre universidade e unidade básica de ensino, e para a interação entre escola, universidade e sociedade. Quando se fala em palestras, é preciso pensar na estrutura necessária para que esse tipo de evento ocorra, como, por exemplo, conhecimento sobre as pesquisas científicas da contemporaneidade acerca do tema, adesão do público escolar e dos pais ou responsáveis pelos adolescentes - tendo em vista, como pudemos ver na fala de Amaro, sobre como a homofobia não está só no espaço da escola, mas também no ambiente familiar. Portanto, seria ingênuo conscientizar só os(as) adolescentes sobre o sofrimento que o patriarcado pode promover através dos seus iguais no ambiente escolar, sendo assim necessário fazer um trabalho que abarque também os envolvidos no processo de criação desses(as) jovens. Sabemos que dialogar com os pais/familiares pode não resolver tudo, mas só permitir o acesso a discussão e criar um ambiente em que haja debate acerca desses temas pode gerar reflexão e mudança no modo como as pessoas convivem com essas diferenças.

Seguindo nesse sentido, e apesar de toda a crítica que fizemos sobre a instituição escola enquanto um ambiente que propicia uma norma LGBTQIA+fóbica, temos que reconhecer que, sendo um espaço intrinsecamente plural, mesmo com as opressões, o ambiente escola propicia, mesmo que a passos lentos, a promoção da igualmente/equidade. Como exemplos temos a fala de Naim, que ao questionarmos como ele se sentia na escola quanto a sua homossexualidade, ele respondeu o seguinte: "me sinto superprotegido, porque lá já não tem muitos casos de homofobia." Ou seja, um trabalho conjunto, de percepção da vivência social do(a) aluno(a) pode ter ensejado na escola de Naim uma ação anti LGBTQIA+fóbica, que permitiu com que o rapaz se sentisse acolhido. Se na escola, lugar de reprodução da norma, mas também de produção de novas concepções, é tão difícil lidar com a diferença, imagine fora dela, na sociedade.

Toda essa discussão nos faz perceber como a escola é um lugar em que há um tensionamento entre o que é tratado como norma e reações que se colocam contra essa normatização, de modo que o conflito aponta para uma dificuldade de saber como lidar com essas questões dentro do contexto escolar, seja na convivência dos alunos, de como abordar esses assuntos travessamente no currículo ou como orientar a equipe técnico-pedagógica na criação de eventos ou como mediadora desses embates. Porém, apesar de toda essa dificuldade, a partir de todos os(as) discentes que entrevistamos, percebemos o espaço da escola, com toda sua pluralidade, além da vivência desse alunado que se inscreve em um lugar que desafia o status quo da heteronormatividade, propicia a esse alunado um entendimento das práticas hierarquizantes instituídas pela construção do gênero, do desejo e da sexualidade, como podemos perceber na fala que usaremos para nos direcionar para a conclusão:

A sociedade é homofóbica, transfóbica, racista. O homem tem que mostrar que é homem todo dia, que é macho. O homem não pode chorar, o homem tem que dominar a porra toda. Se for uma mulher que domina, uma mulher empoderada, ela será considerada piranha. Vou te mostrar como a sociedade é opressora, principalmente com as mulheres. Se um homem pega várias mulheres, é o fodão, mas se uma mulher pegar vários homens, ela é considerada piranha. Então a sociedade é machista. Isso porque os cargos poderosos quem ocupa são os homens, eles acham que a mulher não tem capacidade para ocupar esses cargos. Para acabar coma homofobia, esse assunto precisa ser colocado mais em pauta, dialogar mais, pois o que as pessoas fazem entre 4 paredes só desrespeita a elas. (Amaro, 19 anos, 2o ano do EM).

No relato acima vemos que os adolescentes possuem um entendimento das práticas hierarquizantes instituídas pelo gênero. Com argumento do próprio entrevistado, o homem na sociedade tudo pode enquanto mulheres e LGBTQIA+s só podem se submeter ao gosto dele. Pelo menos esse era o pensando que imperava na sociedade brasileira, porém graças ao enfrentamento político dos movimentos sociais, em especial os feministas e os LGBTQIA+s, as barreiras dos privilégios masculinos estão, paulatinamente, sendo destruídas. 


\section{Palavras finais}

A construção social de expectativas acerca da sexualidade dos jovens é marcada por uma lógica cisheteronormativa e cria uma atmosfera de cobranças sobre crianças e adolescentes que, desde muito cedo, percebem a necessidade de atender a determinadas demandas a fim de serem aceitos. Contudo, conforme percebido durante os relatos das entrevistas, jovens gays, lésbicas, bis, trans, entre outras denominações, enquanto se desenvolvem como sujeitos, identificam em si mesmo que sentem desejos que não coadunam com aquilo que tal sociedade espera deles. Isso cria uma série de problemas de ordem emocional, já que também costuma haver pouco amparo e orientação nos diferentes espaços, inclusive na escola. A família, por exemplo, grupo que socialmente é reconhecido por oferecer instrução, amor e acolhimento, costuma, de acordo com os relatos dos(as) nossos(as) entrevistados(as), não ajudar/não saber auxiliar ao(a) jovem que está descobrindo sua própria orientação sexual ou identidade de gênero. Dessa forma, como pudemos perceber, os(as) entrevistados(as) encontraram diferentes formas de lidar com essas questões, porém, algo que basicamente todos(as) apontaram é que se houvesse mais abertura social para a abordagem de temas que discutissem sobre os(as) LGBTQIA+, faria muita diferença nas suas vidas pessoais e, consequentemente, poderia haver mais legitimação e proteção de suas próprias vidas, os(as) salvando de vivenciar determinadas experiências de preconceito no ambiente escolar, na família e, até mesmo, na sociedade.

A partir de toda a discussão que levantamos aqui, concluímos que a escola, quando atenta aos objetivos, em forma de artigos, expostos na Declaração Universal dos Direitos Humanos (ONU, 1948), deve visar sempre promover em suas práticas educacionais a liberdade de gênero, de orientação sexual, equidade e igualdade, como forma de incluir pessoas que estejam fora do que é tratado como norma socialmente. De acordo com o que afirmamos, a escola sozinha não tem a capacidade de mudar todas as estruturas da sociedade, mas tem como influenciar fortemente na reorganização dos pilares que sustentam as bases dessa cultura. Acreditamos também que os diálogos abertos com a comunidade extraescolar são de extrema valia para as políticas progressistas. Como trouxemos nas análises das falas, é possível promover um debate conjunto com os alunos sobre violência doméstica, e assim abordar o tema da LGBTQIA+fobia, que se insere perfeitamente nos conceitos de violências contemporâneas.

O trabalho pela promoção da igualdade é lento, mas não é impossível de ser feito. Muitos são os condicionamentos a se enfrentar, porém é alcançável. Neste artigo buscamos defender uma educação que seja antirracista, antissexista, anti LGBTQIA+fóbica. O trabalho docente mostra-se profícuo para o enfrentamento de tais mazelas sociais, proporcionando a construção de um ambiente escolar mais acolhedor, empático, afetuoso e que proporcione à sociedade informação e reflexão sobre as diferenças de maneira positiva e inclusiva. Contudo, o compromisso com esta perspectiva pedagógica e social precisa ser uma prática constante, que se amplie cada vez mais na comunidade escolar. 


\section{Referências}

ABRAMOVAY, Miriam; CASTRO, Mary Garcia; SILVA, Lorena Bernadete. Juventude e sexualidade. 1. ed. Brasília, DF: Editora Unesco Brasil, 2004.

AMARAL, Marília dos Santos. Essa boneca tem manual: práticas de si, discursos e legitimidades na experiência de travestis iniciantes. 2012. Dissertação (Mestrado em Psicologia) - Universidade Federal de Santa Catarina, Florianópolis, 2012.

ANDRÉ, Marli Eliza Dalmazo Afonso de; LÜDKE, Menga. Pesquisa em educação: abordagens qualitativas. 1. ed. São Paulo: EPU, 1986.

ARROYO, Miguel. Currículo, território em disputa. 5. ed. Petrópolis: Vozes, 2011.

BOBBIO, Norberto. A era dos direitos. 2. ed. Rio de Janeiro: Elsevier, 2004.

BRASIL. Lei n. ${ }^{\circ}$ 8.069, de 13 de julho de 1990. Dispõe sobre o Estatuto da Criança e do Adolescente e dá outras providências. Brasília, DF: Presidência da República, [1990].

BUTLER, Judith. Critically queer. GLQ: A Journal of Lesbian and Gay Studies, Durham, v. 1, n. 1, p. 17-32, 1993. Disponível em: https://psicanalisepolitica.files.wordpress.com/2014/10/butler-judith-bodies-thats-matter.pdf. Acesso em: 1 maio 2020.

CAETANO, Marcio; GOULART, Treyce Ellen Silva; SILVA JUNIOR, Paulo Melgaço da. "Eu me sentia assim, meio que excluído": performances hegemônicas e as dissidências na escola. In: CASTRO, Mary Garcia; MESSEDER, Suely; MOUTINHO, Laura (org.). Enlaçando sexualidades: uma tessitura interdisciplinar no reino das sexualidades e das relações de gênero. 1. ed. Salvador: EDUFBA, 2016. p. 127-156.

CANDAU, Vera Maria. Educação em Direitos Humanos: políticas curriculares. In: LOPES, Alice Casimiro; MACEDO, Elizabeth (org.) Políticas de Currículo em múltiplos contextos. 1. ed. São Paulo: Cortez, 2006. p. 219-240.

CARVALHO, Nivaldo Moreira; SILVA, Iraci Pereira; WELLER, Wivian. Discussões de gênero e sexualidade no meio escolar e o lugar da jovem mulher no ensino médio In: DAYRELL, Juarez; MOREIRA, Maria Ignez Costa; STENGEL, Márcia (org.). Juventudes contemporâneas: um mosaico de possibilidades. 1. ed. Belo Horizonte: Editora PUC Minas, 2011. p. 273-295. Disponível em: http://portal.pucminas.br/imagedb/documento/DOC_DSC_NOME_ARQUI20120704131151. pdf. Acesso em: 1 abr. 2020.

CHAUI, Marilena; SANTOS, Boaventura de Sousa. Direitos Humanos, Democracia e Desenvolvimento. 1. ed. São Paulo: Cortez, 2013.

CONSELHO NACIONAL DE SECRETÁRIOS DE EDUCAÇÃO (CONSED). Secretaria de Educação lança projeto “Para Nunca Esquecer”. Consed, Rio de Janeiro, 24 maio 2019. Disponível em: http://www.consed.org.br/central-de-conteudos/secretaria-de-educacao-do-rio-de-janeiro-lanca-projeto-para-nunca-esquecer. Acesso em: 7 ago. 2020.

CORREIA, Maria da Conceição Batista. A observação participante enquanto técnica de investigação. Pensar Enfermagem, Lisboa, v. 13, n. 2, 2009. Disponível em: https://comum.rcaap.pt/bitstream/10400.26/23968/1/2009_13_2_30-36. pdf. Acesso em: 16 out. 2014

COSTA, Deane Monteiro Vieira. Escola e juventude: encontros e desencontros. 2005. Dissertação (Mestrado em Educação) - Universidade Federal do Espírito Santo, Vitória, 2005.

DAUSTER, Tania. A invenção do leitor acadêmico: quando a leitura é estudo. Leitura: Teoria \& Prática, Rio de Janeiro, v. 57 , p. $1-15,2001$.

DUQUE, Tiago. Montagens e desmontagens: vergonha, estigma e desejo na construção das travestilidades na adolescência. 2009. Dissertação (Mestrado em Sociologia) - Universidade Federal de São Carlos, São Carlos, 2009.

FERNANDÉZ, Mónica; KLAINER, Rosa. La educancion en derechos humanos em la Argentina: ideias-fuerza de los años ochenta a la actualidad. In: MAGENDZO, Abraham. (org.). Pensamiento e ideias-fuerza de la educación en derechos humanos en Iberoamérica. 1. ed. Santiago: Editora UNESCO/OREALC: Editora OEI, 2009.

FRANGELLA, Rita de Cássia Prazeres; RAMOS, Aura Helena. Currículo de educação em direitos humanos: sentidos em embates/articulações. Revista Educação, Porto Alegre, v. 36, n. 1, p. 14-20, 2013.

LEVI, Giovanni; SCHMITT, Jean-Claude (org.). História dos jovens: da Antiguidade a Era Moderna. Tradução: Cláudio Marcondes, Nilson Moulin e Paulo Neves. 1. ed. São Paulo: Companhia das Letras, 1996. (Volume 1).

MEYER, Dagmar Elisabeth Estermann. Saúde, sexualidade e gênero na educação de jovens, por quê? In: MEYER, Dagmar Elisabeth Estermann et al. (org.). Saúde, sexualidade e gênero na educação de jovens. 1. ed. Porto Alegre: Mediação, 2012. p. 5-12. 
ORGANIZAÇÃO DAS NAÇÕES UNIDAS (ONU). Declaração Universal dos Direitos Humanos. Paris: ONU, 1948. Disponível em: https://www.unicef.org/brazil/declaracao-universal-dos-direitos-humanos. Acesso em: 12 dez. 2020.

POCAHY, Fernando. A pesquisa fora do armário: ensaio de uma heterotopia queer. 2006. Dissertação (Mestrado em Psicologia) - Universidade Federal do Rio Grande do Sul, Porto Alegre, 2006.

RAMOS, Aura Helena. Significações em disputa na constituição do discurso curricular de Educação em Direitos Humanos. Tese (Doutorado em Educação) - Universidade do Estado do Rio de Janeiro, Rio de Janeiro, 2010.

RAMOS, Aura Helena. O lugar da diferença no currículo de Educação em Direitos Humanos. 2. ed. Rio de Janeiro: Quartier, 2011.

RANGEL, Mary. Diversidade: Um compromisso pedagógico da escola. Rio de Janeiro: Wak Editora, 2017. 84 p.

RIOS, Luís Felipe. O Feitiço de Exu: um estudo comparativo sobre parcerias e práticas homossexuais entre homens jovens candomblesistas e/ou integrantes da comunidade entendida do Rio de Janeiro. 2004. Tese (Doutorado em Medicina Social) - Universidade do Estado do Rio de Janeiro, Rio de Janeiro, 2004.

SACAVINO, Susana. Educação em/para os Direitos Humanos: uma construção histórica. 2008. Tese (Doutorado em Educação) - Pontifícia Universidade Católica do Rio de Janeiro, Rio de Janeiro, 2008.

SANTOS, Boaventura de Sousa. Por uma concepção multicultural de direitos humanos. Revista Crítica de Ciências Sociais, Coimbra, n. 48, p. 11-32, 1997.

SANTOS. Se Deus fosse um ativista dos direitos humanos. 1. ed. São Paulo: Cortez, 2014.

SCHOEN-FERREIRA, Teresa Helena. Adolescência através dos Séculos. Psicologia: Teoria e Pesquisa, Brasília, DF, v. 26, n. 2, p. 227-234, abr./jun. 2010.

SECRETARIA DE DIREITOS HUMANOS DA PRESIDÊNCIA DA REPÚBLICA (SDH/PR). Programa Nacional de Direitos Humanos: PNDH-3. Brasília, DF: Editora SDH/PR, 2010.

SILVA, Aida Monteiro. Escola Básica e a Formação da Cidadania: possibilidades e limites. 2000. Tese (Doutorado em Educação) - Universidade de São Paulo, São Paulo, 2000.

SILVA, Tomaz Tadeu da. Documentos de identidade: uma introdução às teorias de currículo. 1. ed. Belo Horizonte: Autêntica, 1999.

WORLD HEALTH ORGANIZATION (WHO). Young People's Health: a challenge for society. Geneva: WHO, 1986.

Data de submissão: 13/01/2021

Data de aceite: $30 / 01 / 2021$ 